\title{
A Review of Inductively Coupled Plasma-Assisted Magnetron Sputter System
}

\author{
Received May 22, 2019; revised August 14, 2019; accepted August 27, 2019
}

Tae Hyung Kim ${ }^{a}$ and Geun Young Yeom ${ }^{\text {a,b,* }}$
aDepartment of Materials Science and Engineering, Sungkyunkwan University, Suwon 16419, Republic of Korea
bSKKU Advanced Institute of Nano Technology (SAINT), Sungkyunkwan University, Suwon 16419, Republic of Korea

*Corresponding author E-mail: gyyeom@skku.edu

\begin{abstract}
For plasma-based deposition techniques, high ionization through high-density plasma plays an important role in improving the deposited film. Various deposition methods such as high-power impulse magnetron sputtering and ion-beam sputtering have been developed for physical vapor deposition technology and are still being studied. Further, studies have been carried out to control the characteristics of the deposited films by directly controlling plasma characteristics using an inductively coupled plasma (ICP) antenna; this is called an ICP-assisted magnetron sputter (ICP MS) technology. The ICP MS method exhibits the characteristics of low resistance, high materials density, and low stress because it can perform processes at low temperatures and with high-density ion bombardment at low energies. Using the ICP-assisted sputter technology, the crystal structure of a thin film can be also controlled. In recent years, devices and thin films that are becoming finer are required to have a low resistance property in a thin film and a low temperature process because of the possible thin-film thermal damage. In this review, some of the important aspects of the ICP MS technology, which can solve problems such as low resistance, high density thin film, and low temperature process, are discussed.
\end{abstract}

Keywords: Sputter, Inductively coupled plasma, Inductively coupled plasma magnetron sputter, Ionization

\section{Sputtering}

Sputter or sputtering refers to the physical removal of atoms from the surface of a material by the collision of energetic particles on the surface of the material. The removal of the atoms from the surface is achieved by momentum transfer between the atoms released and the atoms on the surface adjacent to these atoms. In addition to the sputtering phenomena, various interactions such as surface-neutralization, secondary electron emission, ion implantation, and radiation damage occur when energy-bearing particles collide with the surface of a material. Sputter deposition is one of the most representative physical vapor deposition (PVD) methods, and it is one of the most widely used deposition methods in semiconductor and display fields. Sputter deposition technology was discovered in 1852 by Grove using direct current (DC) to discharge plasma in a vacuum tube for the deposition. These DC diode sputtering devices had disadvantages in that plasma discharge was difficult to achieve at low pressure, and it had a low deposition rate. Thus, many studies focused on improving the sputtering equipment using several approaches. A magnetron sputtering apparatus was developed to assist DC glow discharge using a magnetic field to confine the energetic electrons emitted from the cathode near the cathode surface using an $\mathrm{E} \times \mathrm{B}$ field (electric field vertical to magnetic field).

For deposition or etching equipment that use a plasma discharge method, properties of the plasma are important; among these properties, the characteristics of the ions in plasma have the highest influence on the deposited film. However, the characteristics of the ions in plasma are usually dominated by the ions of the inert sputtering gas while the effect of the ions of the sputtered materials is low. Over the last few years, various ionized sputtering techniques have appeared that can achieve a high degree of ionization of the sputtered atoms [1]. Magnetron sputtering achieves a higher plasma density compared to sputtering without a magnetic field for the same input power. However, if very high power is continuously applied, the target or the deposited thin film may be damaged by the high plasma energy [2-5]; further, there is a power limitation that can be applied to the target. High-power impulse magnetron sputtering, which uses pulse powers composed of extremely high power densities on the order of $\mathrm{kW} \cdot \mathrm{cm}^{-2}$ in short pulses (impulses) of tens of microseconds at a low duty cycle (on/off time ratio) of $<10 \%$ can overcome this limitation [6-9]. However, the deposition rate decreases as the sputtering on-time becomes shorter. Ion beam sputtering (IBS) is another deposition method wherein an ion beam gun is mounted inside a sputter device [10-12]. The ions generated from the ion gun collide with the target or the thin film on the substrate to improve the characteristics of the thin film. The IBS method has an advantage in that it can change the sputter ion incident angle, and the ion flux and energy can be varied separately. However, there is a drawback that the cost of the ion gun is high and large-area processing is difficult owing to the limitation of the deposition area caused by the small beam size. In addition to these two methods, there are other PVD methods that use high ionization; for example, self-sustained sputtering magnetron, which uses highly 
ionized sputtered target atoms as the plasma ions for self-sputtering that can be obtained under high power conditions, and hollow cathode magnetron sputtering, which uses a hollow-shaped cathode to increase plasma density by additionally confining the high-energy electrons near the cathode [13-18].

\section{Magnetron sputter}

A DC sputtering device has disadvantages in that it has a low deposition rate and it is difficult to achieve plasma discharge at low pressure. Thus, studies focused on improving the sputtering apparatus using various approaches. In particular, a magnetron sputtering apparatus was developed to assist DC glow discharge using a magnetic field to confine energetic electrons emitted from the cathode near the cathode surface using an $\mathrm{E} \times \mathrm{B}$ field (electric field vertical to magnetic field).

As shown in Fig. 1, the magnetron sputter device uses a magnetron to increase the ionization rate of electrons. The $\mathrm{N}$ and $\mathrm{S}$ poles are installed such that electrons emitted from the target spiral around the target continuously, and the plasma generating gas constantly causes a collision. The collision probability is proportional to the travel distance of the electron, and consequently, the helical motion around the target increases the travel distance of the electrons and ionization probability. This leads to increased ion bombardment of the target, which provides higher sputtering rates, and consequently, higher deposition rates at the substrate.

There are only a few differences in the design between a conventional magnetron and an unbalanced magnetron. However, the difference in performance between the two types of magnetrons is very significant. In a conventional magnetron, plasma is strongly confined to the target region. A region of dense plasma typically extends $\sim 60 \mathrm{~mm}$ from the target surface. In an unbalanced magnetron, the outer ring of magnets is strengthened relative to the central pole. In this case, not all field lines are closed between the central and outer poles in the magnetron, but some are directed toward the substrate, and some secondary electrons follow these field lines. Consequently, the plasma is no longer strongly confined to the target region but is also allowed to flow out toward the substrate. Thus, high ion currents can be extracted from the plasma without the need to externally bias the substrate. Earlier studies had shown that in some magnetron designs, not all field lines closed in on themselves [19]. However, it was Windows and Savvides who first appreciated the significance of this effect when they systematically varied the magnetic configuration of an otherwise conventional magnetron [20-22]. They and other researchers have subsequently shown that substrate ion current densities of $5 \mathrm{~mA} / \mathrm{cm}^{2}$ and higher, i.e., approximately an order of magnitude higher than that for a conventional magnetron, can be routinely generated when using an unbalanced magnetron [22-24]. A comparison between the plasma confinement obtained in different magnetron modes is shown schematically in Fig. 2.

Thus, in addition to providing a high flux of coating atoms (compared to a basic sputtering source), an unbalanced magnetron acts as a very effective ion source. Furthermore, the ion current drawn at the substrate is directly proportional to the target current. The deposition rate is also directly proportional to the target current. Therefore, unlike other ion-plating processes [25,26], the ion-to-atom arrival ratio at the substrate remains constant with an increasing deposition rate [27-29].

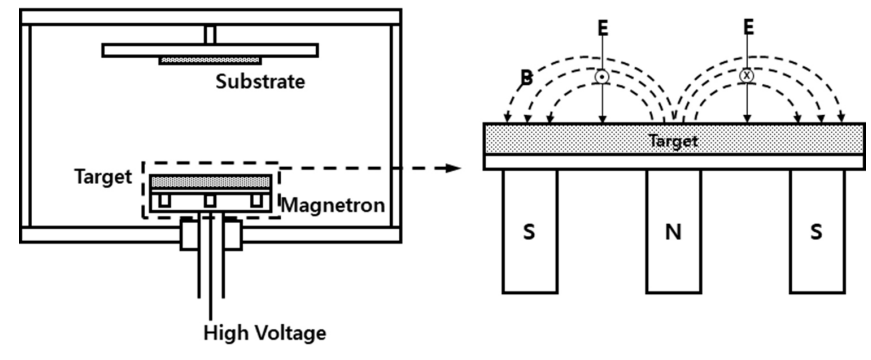

Figure 1. Schematic of magnetron sputter system.

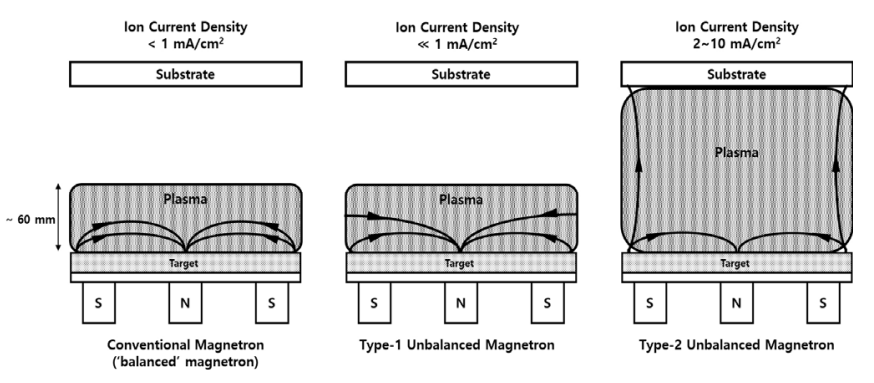

Figure 2. Schematic representation of the plasma confinement observed in conventional and unbalanced magnetrons (Kelly et al. [28]).

\section{Inductively coupled plasma-assisted magnetron sputter (ICP MS)}

Radio frequency (RF) ICPs have been widely studied for over 130 years. The basic concept for generating an ICP stems from Faraday's law, $\nabla \times \mathrm{E}=-\frac{\partial \mathrm{B}}{\partial \mathrm{t}}$; RF current flowing into an antenna coil induces a time-varying magnetic field, and this magnetic field produces an induction field that generates and sustains the plasma. The ICP source can generate plasma at a very low pressure $(\sim 1$ mTorr) and with high density characteristics $\left(10^{11}-10^{12} \mathrm{~cm}^{-3}\right)$. In addition, owing to the flexibility of the antenna structure, the ICP source is used in various equipment such as the deposition process, etch process, and treatment in various forms [30-32].

Among various ionization PVD methods, ICP MS is a magnetron sputter (MS) method that uses an ICP in addition to the near the cathode. An ICP antenna is mounted near a magnetron source to discharge the ICP plasma, thereby improving the characteristics of the deposited film by directly increasing plasma ionization and bombardment during sputter deposition. These allow more energetic ions from the plasma formed from the plasma gas and the particles emitted from the target to reach the surface of the substrate as compared to a typical sputter device, as shown in Fig. 3. Various studies have been carried out to control the characteristics of the deposited thin films by applying ICP additionally during sputtering. Through magnetron sputtering assisted with ICP, high-quality thin films can be obtained using a low temperature process, and other material properties such as the structure of the deposited thin films can be controlled [33-57].

Table I summarizes the results of a comparison between the conventional magnetron sputter device and the ICP-assisted magnetron sputter device. The ICP-assisted sputter device has various advantages such as high ionization efficiency, processing at very low pressures, and control of the deposited film properties owing to the 


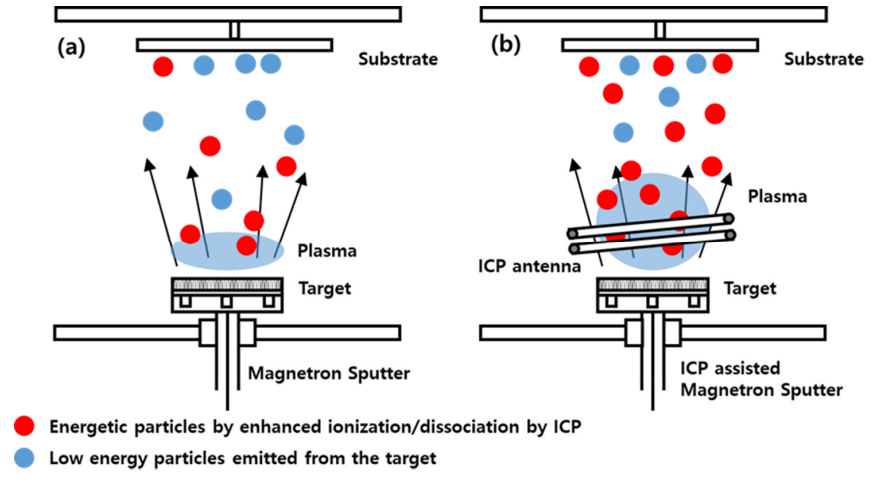

Figure 3. (Color online) Difference between (a) magnetron sputter system and (b) ICP-assisted magnetron system (ICP MS).

Table I. Comparison of characteristic differences between conventional magnetron sputter and ICP assisted sputter system.

\begin{tabular}{ccc}
\hline & Conventional MS & ICP MS \\
\hline Deposition rate & Good & Good \\
Plasma density & Middle & High \\
Working pressure & Low $(<5$ mTorr $)$ & Very low $(<1$ mTorr $)$ \\
Film property control & None & Possible \\
Particle issue & None & Existence \\
\hline
\end{tabular}

additional plasma discharged by the ICP antenna. However, one of the biggest problems to commercializing this process is that target materials are deposited on the antenna during the sputtering process. If this problem can be solved, this process is expected to become a very efficient sputtering process.

\section{1) Plasma properties of ICP MS}

Since ICP MS is a plasma-based deposition system, it is very important to analyze and understand the plasma characteristics generated during the deposition. A typical ICP MS system is as shown in Fig. 4, which was investigated by Setsuhara et al. [33]; in their study, an Al target was used and its plasma characteristics were analyzed. A three-turn ICP antenna was mounted on the magnetron, DC power was applied to the magnetron, and $13.56 \mathrm{MHz}$ RF power was applied to the ICP antenna to generate the plasma in front of the magnetron. A Langmuir probe was installed near the ICP antenna at $50 \mathrm{~mm}$ to measure the plasma density. The magnetron target voltage was fixed at $-200 \mathrm{~V}$, and the power of the ICP antenna was increased from 0 to $400 \mathrm{~W}$. The results of the measured electron densities for different operating pressures are shown in Fig. 5. The pressure was varied from 2 mTorr (0.2 Pa) to $39 \mathrm{mTorr}$ (5.2 Pa). As shown in Fig. 5, when the RF power to the ICP source was not applied in addition to the DC to the magnetron source, the magnetron discharge could be sustained at an Ar pressure higher than $0.2 \mathrm{mTorr}$; further, the electron density was limited to the order of $10^{9} \mathrm{~cm}^{-3}$ at pressure as high as 39 mTorr. However, the application of the RF power to the ICP antenna in addition to the DC power to the magnetron in this magnetron system significantly enhanced the electron density by two orders of magnitude, and sustainable discharge at pressures as low as 0.2 mTorr were observed. In addition, the electron temperature was found to be in the range $2-4 \mathrm{eV}$ [33]. Further, they compared the ion-to-neutral

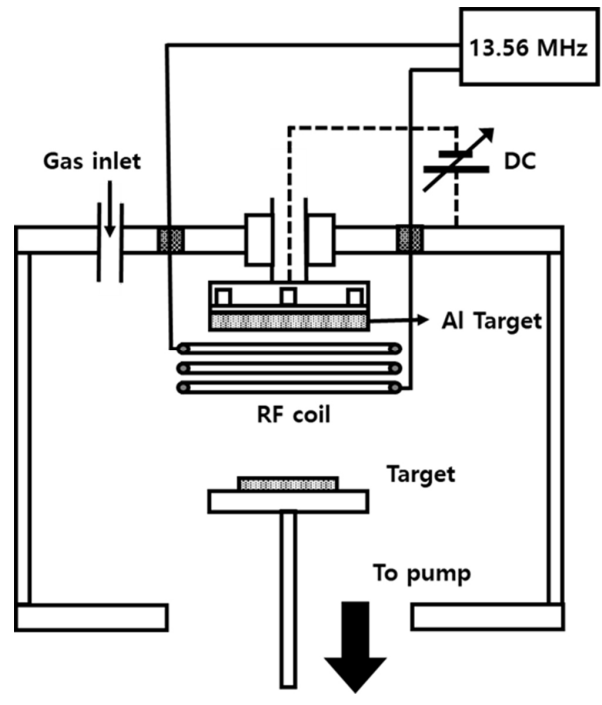

Figure 4. Schematic of a typical magnetron sputtering source equipped with an ICP antenna (Setsuhara et al. [33]).

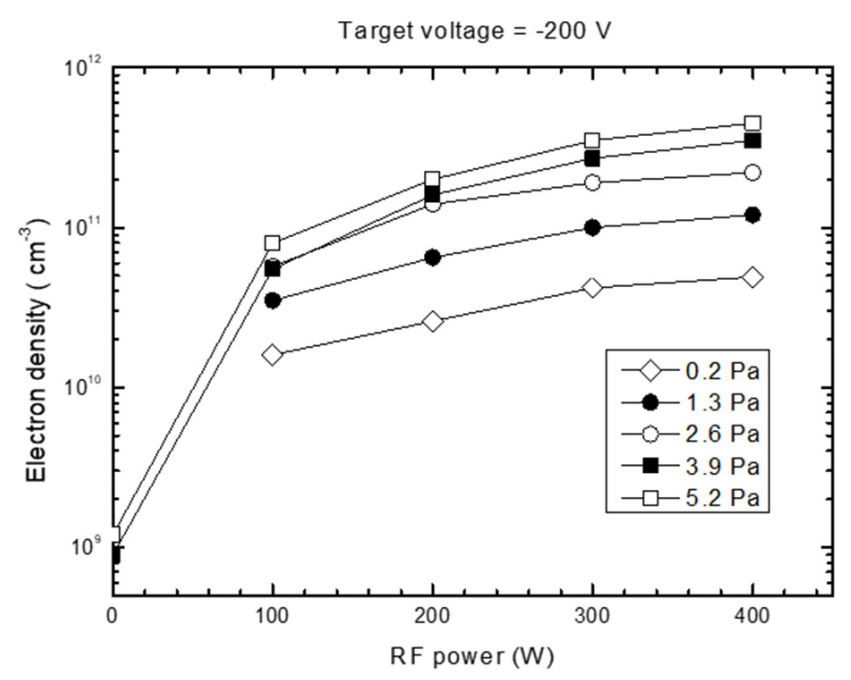

Figure 5. Electron density measured as a function of RF power and Ar pressure (Setsuhara et al. [33]).

ratio of $\mathrm{Ar}$ and $\mathrm{Al}$ atoms sputtered from the target using optical emission spectroscopy and the increased ionization rate with increasing ICP RF power was confirmed. In addition, it was found that, as the ICP RF power increases, the target current related to the sputter rate also increased [34]. The change in the ion species in the plasma were also observed in the operation of ICP during magnetron sputtering, and this can affect the characteristics of the deposited thin film $[33,44,56]$.

\section{2) Deposition rate}

Higher deposition rate during sputter deposition for higher throughput is one of the most important factors for lower process cost. Improved sputtering using ICP in ICP MS is confirmed by several studies [34-36]. This is because, when the ICP RF power is added and increased during ICP MS, the current of the target is increased because of the increased plasma density near the target by 


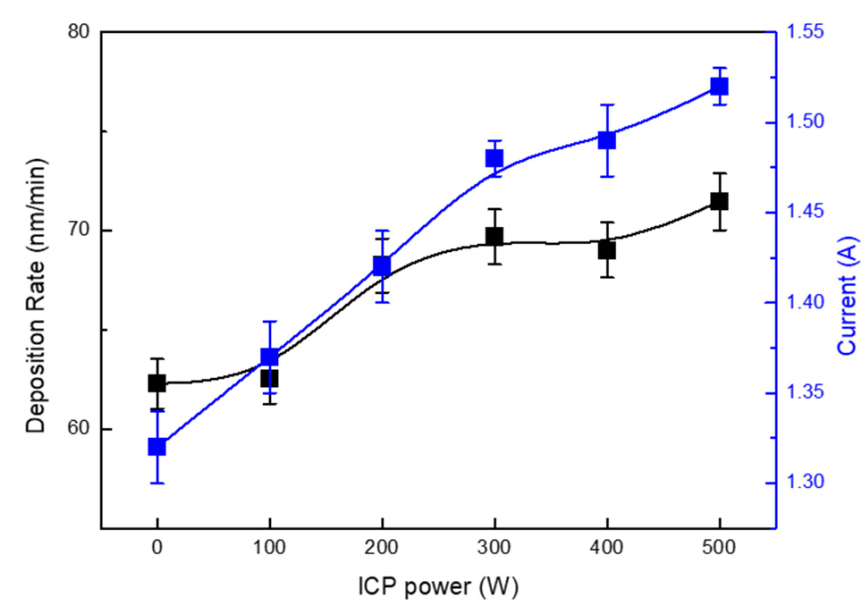

Figure 6. (Color online) Deposition rate of $\mathrm{W}$ film and magnetron current measured as a function of ICP power (from 0 to $500 \mathrm{~W}$ ) at room temperature (Lee et al. [34]).

the additional ionization of the gas by the ICP, which increases the deposition rate. The study by Lee et al. [34] showed that, for tungsten (W) film deposition by varying ICP RF power in an ICP MS system while applying $500 \mathrm{~W}$ of the constant $\mathrm{DC}$ power to the $\mathrm{W}$ target, an increased $\mathrm{W}$ target current was observed as the RF power to the ICP was increased as shown in Fig. 6. Thus, the deposition rate of a W film under these conditions was increased, as shown in the figure. The increased ICP power increased the deposition rate by increasing the sputtered atom flux caused by the increased $\mathrm{Ar}^{+}$ion density near the magnetron surface. Further, in the study on the deposition of amorphous InGaZnOx (a-IGZO) using a different type of ICP MS system, the increased deposition rate of a-IGZO with increasing RF power of ICP was also observed [35,36]. Through these studies, it can be confirmed that the deposition rate is increased by using additional ICP during magnetron sputtering at a constant DC voltage. In fact, the deposition rate can be increased by increasing the DC voltage or DC current to the magnetron sputter target during magnetron sputtering; however, studies on ICP MS showed that process efficiency can also be improved in addition to the increased deposition rate without degrading the characteristics of the deposited thin films [34-36].

\section{3) Deposition temperature}

Over the last decade, numerous research studies on sputter deposition have been carried out for flexible displays or electronic devices. Among these studies, many are related to low temperature deposition of materials to perform the deposition process on substrates such as polymer substrates for flexible displays [37-40] and silicon substrates for nanoelectronics. For flexible displays, the substrates are damaged at higher deposition temperature (e.g., polymer substrates), and silicon substrates for nanoelectronics are damaged by rapid diffusion as the size of the electronic device becomes smaller. Therefore, various studies were conducted to obtain high-quality thin films by using a sputter processes at low temperatures [41-45]. Materials such as indium tin oxide, IGZO, and Al-doped $\mathrm{ZnO}$ (AZO), which are well known as transparent conducting oxide (TCO) materials, are generally deposited at high temperatures during sputter deposition, or they are annealed at high temperatures after deposition at low temperatures to obtain improved material properties of the thin film [46-48]. However, because the polymer substrate cannot be

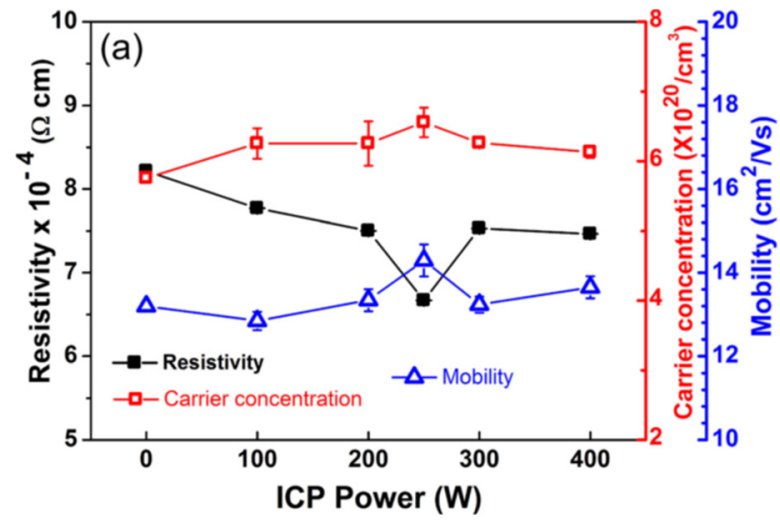

Figure 7. (Color online) Electrical properties of the deposited film as a function of ICP power (Sahu et al. [44]).

processed at a high temperature, a lower temperature TCO deposition process condition is required. Sahu et al. [44] deposited a highly conductive transparent AZO film using ICP MS without heating the substrate, and the results are shown in Fig. 7. Owing to the high ionization efficiency of ICP-assisted magnetron plasma, high-quality thin films could be obtained even at a low temperature. The improved characteristics of the AZO film deposited at room temperature were related to the characteristics of the highly ionized plasma during the deposition process. Jung et al. [41] deposited the AZO film at low temperatures $\left(<150{ }^{\circ} \mathrm{C}\right)$ using an ICP MS system and obtained material characteristics with a high transmittance of over $80 \%$ and low electrical resistivity of $10^{-3} \Omega \mathrm{cm}$. Takenaka et al. [45] deposited aIGZO films for the application as an active layer of thin-film transistors (TFTs) at a low temperature, and the improved electrical characteristics of TFTs were observed by the ICP MS of a-IGZO films when applied to the device.

\section{4) Properties of deposited film}

In various thin film deposition studies using the ICP MS system, there are many reports which show that the controlled ICP applied during MS improved the characteristics of the deposited films [4357]. For example, using controlled plasma for TCO films, the resistance decreased, the mobility increased, and the transparency improved by the addition of the controlled ICP under the same magnetron sputter conditions $[34,44,49]$. The cause of the improved thin film characteristics was investigated, and the results showed that improved material properties are related to the change in the thin film structure and the density of the thin film caused by the changes in the characteristics of ion species in the plasma to the thin film $[42,44,49,50]$. In addition, some researchers found changes in mechanical properties such as hardness or stress and the changes in electrical properties using ICP MS [50-52].

\section{Chemical property}

The changes in the composition and binding energy of the components in the thin film are some of the factors that directly affect the change in the chemical properties of the deposited thin films. In general, the composition of the deposited thin film during the reactive sputter deposition of compounds such as oxides or nitrides can be changed by varying the composition ratio of the target during the magnetron sputtering of the compounds or by changing the reactive 

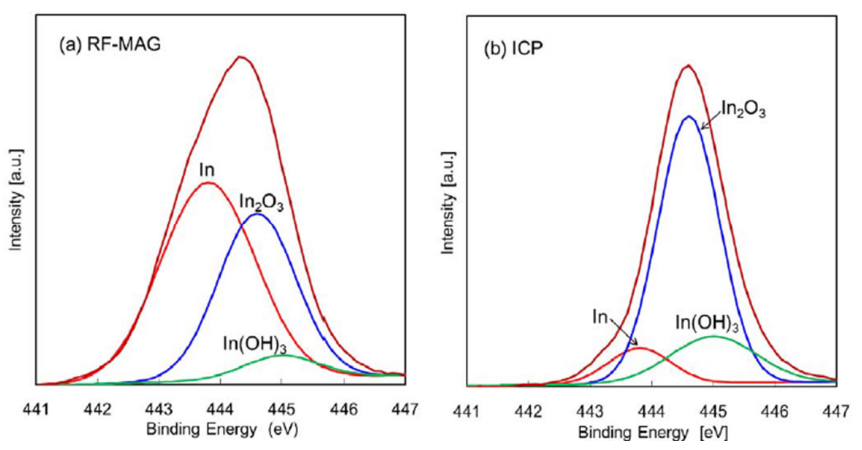

Figure 8. (Color online) $1 n_{3 d 5 / 2}$ XPS spectra in a-IGZO films deposited using (a) RF magnetron without ICP and (b) ICP MS (Matsuo et al. [49]).

gas percentages such as oxygen and nitrogen in the gas mixture. However, during ICP MS, because the ICP changes the dissociated radical concentrations of nitrogen or oxygen mixed with Ar, the composition of the compound thin film can be changed without changing the reactive gas percentages during reactive sputtering $[41,42,45,53]$. ICP MS also changes the binding energy of each component in the deposited thin film by changing the bonding characteristics during the deposition because of the increased ion density in the plasma in addition to the changes in the radical characteristics of the reactive gas in the plasma [44,49,57]. Matsuo et al. [49] deposited a-IGZO thin films using ICP-assisted RF magnetron sputtering and their characteristics were compared with thin films deposited without ICP assistance, i.e., with only RF magnetron sputtering. They fabricated bottom-gate type TFT devices on thermally oxidized $\mathrm{SiO}_{2} / \mathrm{Si}$ substrates using deposited a-IGZO thin films as the active layer and the reliability of the devices. The a-IGZO (In:Ga: $Z n=1: 1: 1$ ) films were deposited with $2 \% \mathrm{O}_{2} / \mathrm{Ar}$ gas ratio at room temperature. The changes in the binding energies of a-IGZO thin films deposited by ICP-assisted RF magnetron sputtering and RF magnetron sputtering without ICP assistance were analyzed by X-ray photoelectron spectroscopy (XPS) and the results are shown in Fig. 8. As shown in Fig. 8, when the $\operatorname{In}_{3 \mathrm{~d} 5 / 2}$ XPS spectra were compared, higher metal-oxide binding in addition to the higher oxygen percentage was observed for ICP-assisted RF magnetron sputtering compared to RF magnetron sputtering, which made the TFTs more stable [49]. Sahu et al. [44] deposited aluminum zinc oxide (AZO) at a low temperature using ICP MS with different ICP powers from 0 to 400 $\mathrm{W}$, and they analyzed the atomic percentages and binding energies of each component in the film using XPS as shown in Fig. 8. As shown in Figs. 9(a)-(c), XPS narrow scan data of the binding peaks related to $\mathrm{Al}_{2 \mathrm{p}}, \mathrm{O}_{1 \mathrm{~s}}$, and $\mathrm{Zn}_{2 \mathrm{p}}$ did not noticeably change with increasing ICP power, which indicate that there are no significant changes in binding energies and compositions. However, the corresponding valence band spectra near the Fermi surface in Fig. 9(d) showed a higher $\mathrm{Zn}_{3 \mathrm{~d}}$ band and a weaker $\mathrm{O}_{2 p}$ band with increasing ICP power. The weaker intensity of the $\mathrm{O}_{2 p}$ band is an indication of the high $\mathrm{O}$ vacancy, which implies that there is an increase in $\mathrm{O}$ vacancies in the material as the ICP power increases. The increase in $\mathrm{O}$ vacancies in the AZO film contributes to the enhancement of the carrier concentration and a decrease in film resistivity [44]. Lee et al. deposited a W thin film with ICP MS as an application to the interconnect materials for nanoelectronics, and they measured $\mathrm{O}_{1 \mathrm{~s}}$ peak intensities using XPS in the deposited $\mathrm{W}$ thin film as the impurity in the film for different ICP
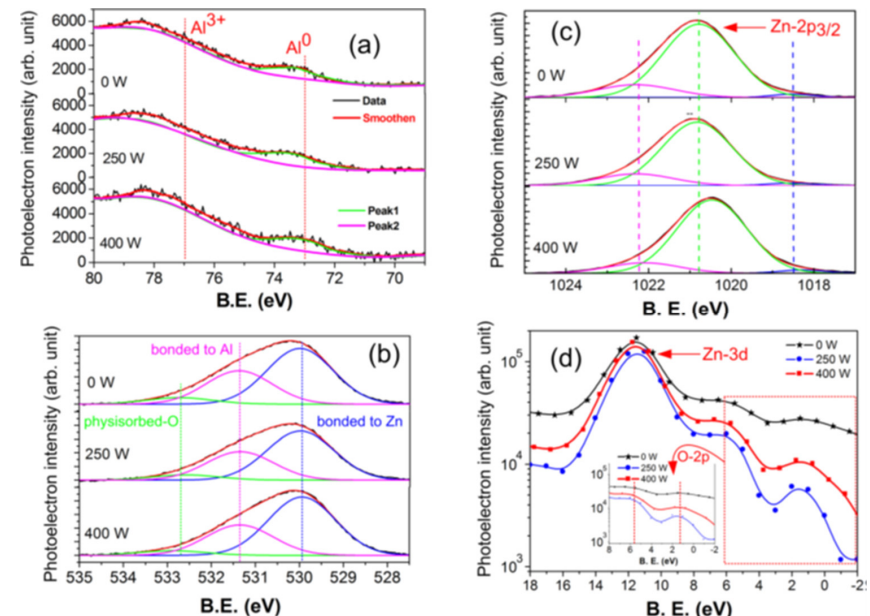

Figure 9. (Color online) Core level XPS spectra of (a) $A_{2 p}$, (b) $O_{1 s}$, and (c) $Z n_{2 p}$ in some selected samples prepared at different ICP powers. (d) is the corresponding valence band spectra near the Fermi surface. The inset in (d) shows the magnified view of the dashed line showing the Al-induced impurity band near the Fermi level (Sahu et al. [44]).

powers. After the XPS analysis of the $\mathrm{W}$ thin films deposited at different ICP powers, they found that the $\mathrm{O}_{1 \mathrm{~s}}$ peak intensities decreased with increasing ICP power indicating decreased oxygen impurity percentages with increasing ICP power during sputtering. The decreased oxygen impurity percentage in the $\mathrm{W}$ film with increasing ICP power was related to the removal of adsorbed oxygen impurity on the $\mathrm{W}$ thin film surface during sputter deposition caused by enhanced low energy $\mathrm{Ar}^{+}$ion bombardment at higher ICP power, which enhances the lower oxygen incorporation in the film [34].

\section{Mechanical property}

Thin films deposited by various methods including sputter deposition improve the chemical and electrical properties; similar improvement are also observed in mechanical characteristics such as hardness, adhesion strength, and wear resistance, and changes in mechanical characteristics caused by ICP MS have also been investigated [50-52]. In the case of Lim et al. [50], a TiN film was deposited to a thickness of about 2 to $3 \mu \mathrm{m}$ with an ICP MS using a titanium (Ti) target and an $\mathrm{Ar} / \mathrm{N}_{2}$ mixed gas. Meanwhile, DC power to the magnetron target was fixed and ICP power $(13.56 \mathrm{MHz})$ was increased from 0 to $600 \mathrm{~W}$. They observed that, as the ICP power increased, the hardness, Young's modulus, compressive residual stress, and wear resistance increased. Figure 10 shows the results of the change in hardness and calculated TiN film density using Rutherford backscattering spectrometry as a function of ICP power. As shown in the figure, the TiN hardness increased with increasing ICP power, and there was an abrupt change from about 2500 to $6000 \mathrm{HK}_{0.01}$ between 200 and $300 \mathrm{~W}$. The density was gradually increased with increasing ICP power, and it showed the same trend as other mechanical properties. The improved mechanical properties with an increase in ICP power are attributed to the increase in ion bombardment caused by the increased ion density in the plasma at higher ICP power. A higher film density with increasing ICP power could be confirmed by SEM observation of thin films deposited at different ICP powers. The cross-sectional images of the TiN coatings in Fig. 11 show that the thin film deposited in the absence of ICP power exhibited an open and 


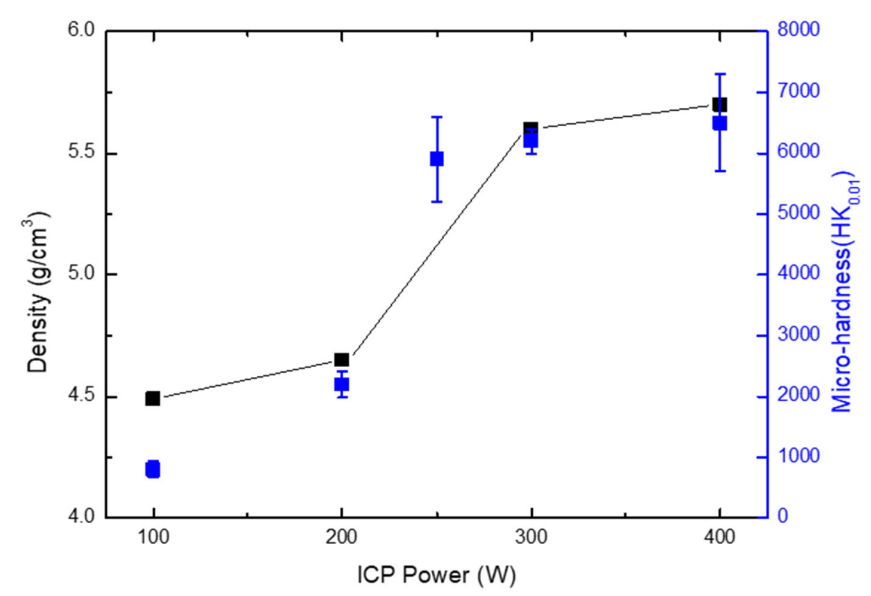

Figure 10. (Color online) Change in the materials density and microhardness of TiN with the ICP power (Lim et al. [50]).
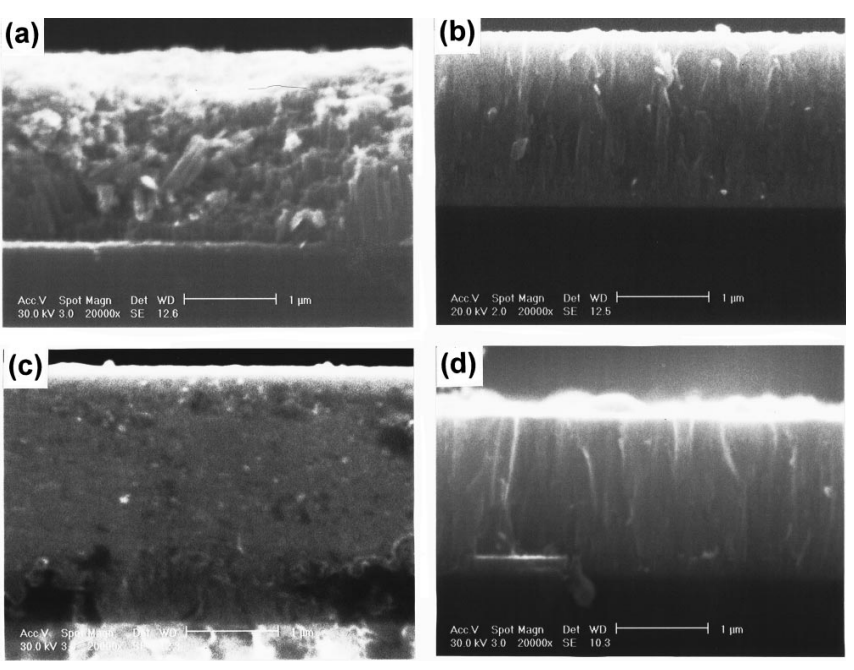

Figure 11. Cross-sectional SEM images of TiN. (a) without ICP, (b) with ICP power of $200 \mathrm{~W}$, (c) with ICP power of $400 \mathrm{~W}$, and (d) dc TiN (Lim et al. [50]).

columnar structure as shown in Fig. 11(a), while dense film morphologies were observed for the films deposited with ICP power. Further, a columnar structure could be found in thin films deposited with a substrate bias (dc TiN) without ICP power as shown in Fig. 11(d). At a higher ICP power ( $400 \mathrm{~W})$, the columnar structure was not observed as shown in Fig. 11(c) [50]. Li et al. [51] deposited Ti-Si-N thin films using an ICP MS and observed improvements in mechanical properties similar to the results obtained by Lim et al. [50]. When ion energy in the plasma was measured during the operation of the ICP MS, a low energy ion flux of $\sim 22 \mathrm{eV}$ was observed with a high current density of the electrode $\left(\sim 2.0 \mathrm{~mA} / \mathrm{cm}^{2}\right)$ caused by plasmas of low energy and high density with the ICP. In addition, the thin films of improved film properties with small biaxial compressive stresses $(<1.5 \mathrm{GPa})$ were successfully synthesized at low deposition temperatures $\left(<150^{\circ} \mathrm{C}\right)$ using the ICP MS.

\section{Film structure}

Film structure is closely related to the physical, chemical, and electrical characteristics of the deposited thin film; therefore, a tech-

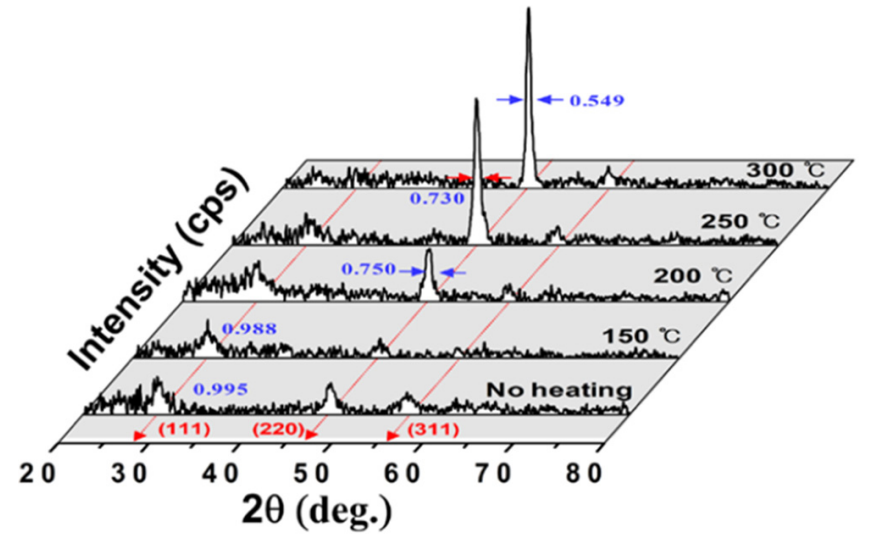

Figure 12. (Color online) HRXRD analysis showing different preferred grain orientations as a function of temperature. The evolution of the peaks corresponding to the (220) plane at higher temperature are also presented (Shin et al. [56]).

nique in forming a required film structure is an important deposition technique. Further, many studies identified a change in the structure of thin films by ICP MS [51,53-57]. Shin et al. [56] studied the fabrication of hydrogenated nanocrystalline silicon (nc-Si:H) at low temperatures $\left(<300{ }^{\circ} \mathrm{C}\right)$ using an ICP MS. A nc-Si:H has been a subject of widespread interest as a candidate for replacing hydrogenated amorphous silicon (a-Si:H) owing to its potential applications in silicon-based devices such as optoelectronic devices, thin-film transistors for flat panel displays, and thin-film solar cells. In the case of conventional nc-Si:H, it is synthesized by plasma enhanced chemical vapor deposition (PECVD). However, low deposition rates and the use of toxic gases such as silane $\left(\mathrm{SiH}_{4}\right)$ for PECVD of nc-Si:H are impediments to high quality films and low fabrication cost. Instead of the PECVD method, using ICP-assisted RF magnetron sputtering uses the ICP RF (at $13.56 \mathrm{MHz}$ ) power up to $500 \mathrm{~W}$ and the RF power supplied to the magnetron to $700 \mathrm{~W}, \mathrm{nc}-\mathrm{Si}: \mathrm{H}$ was deposited with a silicon target at the operating pressure of $3 \mathrm{mTorr}$ and a high hydrogen concentration $\left(100 \times \mathrm{H}_{2} /\left(\mathrm{Ar}+\mathrm{H}_{2}\right)\right)$ of $70 \%$. Figure 12 shows high-resolution X-ray diffraction (HRXRD) patterns of nc-Si:H films deposited at different substrate temperatures from room temperature to $300{ }^{\circ} \mathrm{C}$. The XRD spectra showed three distinct peaks at $2 \theta$ $=28.18^{\circ}, 47.10^{\circ}$, and $55.62^{\circ}$ that correspond to the (111), (220), and (311) crystal planes of $\mathrm{Si}$, which indicates that crystalline phases are formed in all deposition temperature conditions including room temperature. In fact, these diffraction peaks of the deposited silicon films indicate the random distribution of nanocrystals in an amorphous Si matrix [56]. Further, it is known that the (110) orientation can arise from random nucleation [58,59] while (220) preferential growth may be caused by the growth of thermodynamically preferred grains. Therefore, it can be understood that ICP assistance during magnetron sputter deposition affected the crystal growth orientation in addition to the formation of nc-Si:H in the amorphous silicon phase by the increased ion energy caused by the ICP plasma.

Vanadium dioxide $\left(\mathrm{VO}_{2}\right)$ is increasingly attracting interest because of its metal-insulator transition phenomena that show remarkable changes in resistivity at temperatures around $68{ }^{\circ} \mathrm{C}[53,60]$. Nihei et al. [53] studied the characteristics of $\mathrm{VO}_{2}$ by depositing it using an ICP MS for the RF magnetron power of $200 \mathrm{~W}$ with/without ICP power of $250 \mathrm{~W}$, and at different substrate temperatures/operating pressures. A single crystalline sapphire $\left(\mathrm{Al}_{2} \mathrm{O}_{3}\right)(001)$ was used as a 


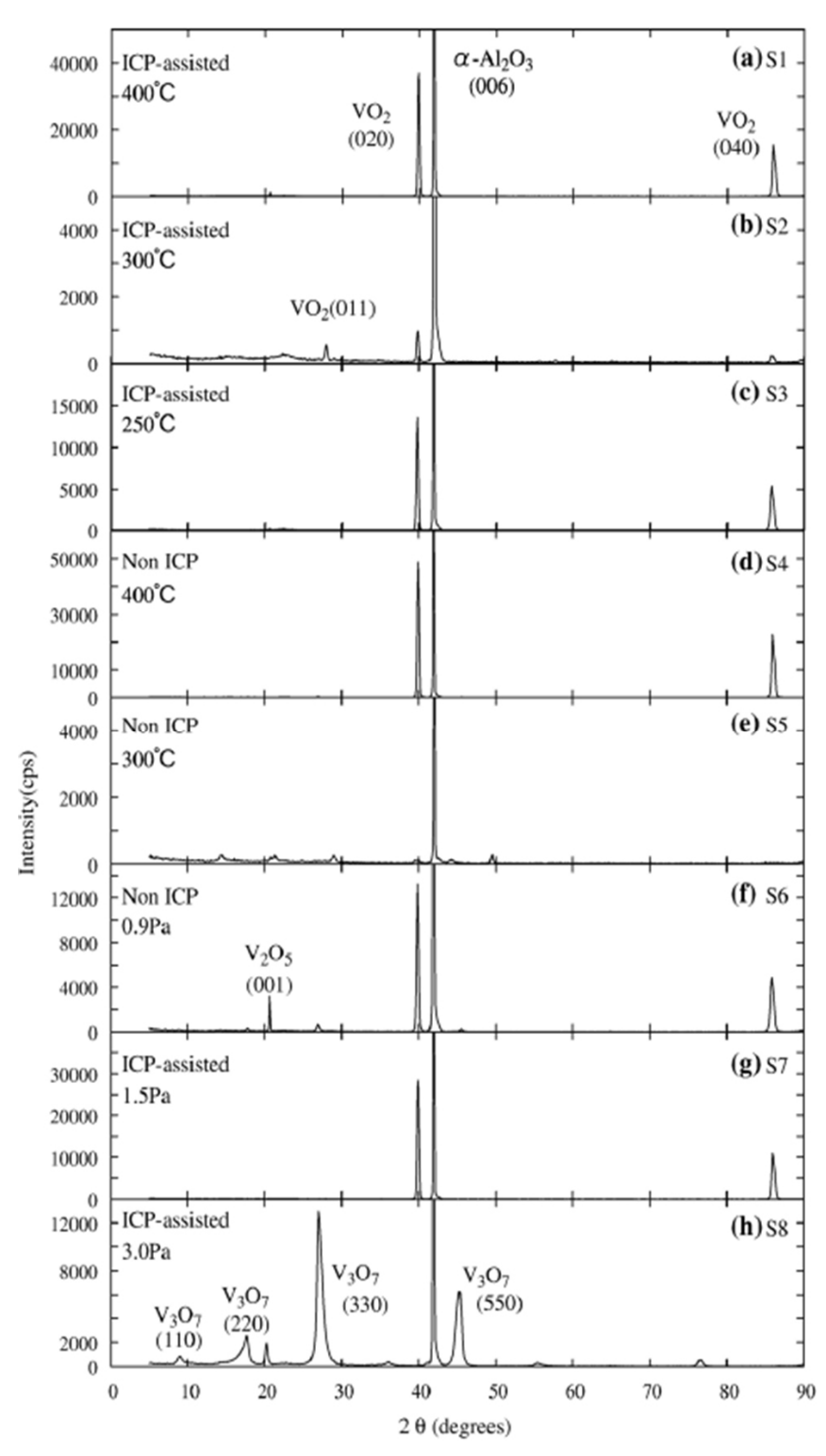

Figure 13. XRD results on the deposited $\mathrm{V}_{\mathrm{x}} \mathrm{O}_{\mathrm{y}}$ thin films for various conditions of ICP power assistance, substrate temperature, and operating pressure (Nihei et al. [53]).

Table II. Deposition conditions for samples labeled S1-S8.

\begin{tabular}{ccccccc}
\hline No. & $\begin{array}{c}\text { ICP } \\
(\mathrm{W})\end{array}$ & $\begin{array}{c}\mathrm{RF} \\
\text { Power } \\
(\mathrm{W})\end{array}$ & $\begin{array}{c}\mathrm{O}_{2} \text { flow } \\
(\mathrm{sccm})\end{array}$ & $\begin{array}{c}\mathrm{T}_{\mathrm{s}} \\
\left({ }^{\circ} \mathrm{C}\right)\end{array}$ & $\begin{array}{c}\text { Total } \\
\text { pressure } \\
(\mathrm{Pa})\end{array}$ & $\begin{array}{c}\text { Film } \\
\text { thickness } \\
(\mathrm{nm})\end{array}$ \\
\hline S1 & 250 & 200 & 0.5 & 400 & 0.4 & 510 \\
S2 & 250 & 200 & 0.5 & 300 & 0.4 & 360 \\
S3 & 250 & 200 & 0.5 & 250 & 0.4 & 490 \\
S4 & Non & 300 & 0.5 & 400 & 0.4 & 540 \\
S5 & Non & 300 & 0.5 & 300 & 0.4 & 510 \\
S6 & Non & 300 & 0.5 & 400 & 0.9 & 580 \\
S7 & 250 & 200 & 0.5 & 400 & 1.5 & 220 \\
S8 & 250 & 200 & 0.5 & 400 & 3.0 & 250 \\
\hline
\end{tabular}

substrate. Figure 13 shows the $\mathrm{XRD}$ results on the deposited $\mathrm{V}_{\mathrm{x}} \mathrm{O}_{\mathrm{y}}$ thin films for various conditions of ICP power assistance, substrate temperature, and operating pressure. Various $\mathrm{V}_{\mathrm{x}} \mathrm{O}_{\mathrm{y}}$ thin films were grown under different conditions (Table II); however, ICP-assisted sputtering enabled stoichiometric $\mathrm{VO}_{2}$ structure without the appearance of other phases up to a pressure of $11 \mathrm{mTorr}(1.5 \mathrm{~Pa})$ as shown in Fig. 13(g). At a pressure of $22 \mathrm{mTorr}(3.0 \mathrm{~Pa})$, only oriented growth of $\mathrm{V}_{3} \mathrm{O}_{7}$ was obtained, even with the ICP-assisted sputtering, as shown in Fig. 13(h) [53].

\section{Summary}

Studies using ICP MS for improving deposited films were reviewed. The studies showed that high-quality thin films can be obtained at low temperature conditions owing to the high-ionization characteristics of the plasma, using ICP MS. The improved thin film properties are related to the increased ion bombardment effect or ion species control due to the high plasma density. The ICP assistance during magnetron sputtering was useful not only for changing the chemical and electrical properties but also for controlling the crystal structure of the deposited thin film. The thin film with higher material density obtained via ICP assistance during the magnetron sputtering can be applied to electronic devices and thin film materials requiring mechanical properties such as high wear resistance and low stress characteristics. Recently, this ICP MS technology has been applied to new fields such as graphene synthesis at low temperatures [61]. Even though various advantages can be obtained using ICP assistance during magnetron sputtering, there are some issues that needs to be improved; for example, a particle issue where the deposition material builds up on the ICP antenna. However, there is a possibility that ICP MS deposition technology can be a solution to solving problems such as achieving higher electrical resistance of the metal thin film for extremely small devices and film thickness, and minimizing damage due to high process temperatures.

\section{Acknowledgements}

This research was supported by the Basic Science Research Program through the National Research Foundation of Korea (NRF) funded by the Ministry of Science and ICT (NRF-2018R1A2B6001 019).

\section{References}

[1] U. Helmersson, M. Lattemann, J. Bohlmark, A. P. Ehiasarian, and J. T. Gudmundsson, Thin Solid Films 513, 1 (2006).

[2] L. Holland and S. M. Ojha, Thin Solid Films 58, 107 (1979).

[3] S. Samukawa, Y. Ishikawa, S. Kumagai, and M. Okigawa, Jpn. J. Appl. Phys. 40, L1346 (2001).

[4] J. Bao, H. Shi, J. Liu, H. Huang, P. S. Ho, M. D. Goodner, M. Moinpour, and G. M. Kloster, J. Vac. Sci. Technol. B 26, 2460 (2008).

[5] D. Pasquariello, C. Hedlund, and K. Hjort, J. Electrochem. Soc. 147, 2699 (2000).

[6] V. Kouznetsov, K. Macák, J. M. Schneider, U. Helmersson, and I. Petrov, Surf. Coat. Technol. 122, 290 (1999).

[7] D. V. Mozgrin, I. K. Fetisov, and G. V. Khodachenko, Plasma Phys. Rep. 21, 400 (1995). 
[8] K. Macák, V. Kouznetsov, J. Schneider, U. Helmersson, and I. Petrov, J. Vac. Sci. Technol. A, Vac. Surf. Films 18, 1533 (2000).

[9] A. P. Ehiasarian, R. New, W. -D. Münz, L. Hultman, U. Helmersson, and V. Kouznetsov, Vacuum 65, 47 (2002).

[10] H. Windischmann, J. Appl. Phys. 62, 1800 (1987).

[11] J. L. Ong, L. C. Lucas, W. R. Lacefield, and E. D. Rigney, Biomater. 13, 249 (1992).

[12] J. Li, D. Stein, C. McMullan, D. Branton, M. J. Aziz, and J. A. Golovchenko, Nature 412, 166 (2001).

[13] A. Anders, S. Anders, M. A. Gundersen, and A. M. Martsinovskii, IEEE T. Plasma SCI. 23, (1995).

[14] W. M. Posadowski and A. Brudnik, Vacuum 53, 11 (1999).

[15] A. Wiatrowski and W. M. Posadowski, J. Vac. Sci. Technol. A 26, 1277 (2008)

[16] J. J. Cuomo and S. M. Rossnagel, J. Vac. Sci. Technol. A 4, 393 (1986).

[17] Z. Wang and S. A. Cohen, J. Vac. Sci. Technol. A 17, 77 (1999).

[18] E. Klawuhn, G. C. D’Couto, K. A. Ashtiani, P. Rymer, M. A. Biberger, and K. B. Levy, J. Vac. Sci. Technol. A 18, 1546 (2000).

[19] A. R. Nyaiesh, Thin Solid Films 86, 267 (1986).

[20] B. Window and N. Savvides, J. Vac. Sci. Technol. A 4, 196 (1986).

[21] B. Window and N. Savvides, J. Vac. Sci. Technol. A 4, 453 (1986).

[22] B. Window and N. Savvides, J. Vac. Sci. Technol. A 4, 504 (1986).

[23] R. P. Howson, H. A. J'Afer, and A. G. Spencer, Thin Solid Films 193, 127 (1990).

[24] W. D. Sproul, Vacuum 51, 641 (1998).

[25] R. F. Bunshah and R. S. Juntz, J. Vac. Sci. Technol. 9, 1404 (1972).

[26] R. J. Hecht and J. R. Mullaly, J. Vac. Sci. Technol. 12, 836 (1975).

[27] P. J. Kelly and R. D. Arnell, Surf. Coat. Technol. 97, 595 (1997).

[28] P. J. Kelly and R. D. Arnell, Vacuum 56, 159 (2000).

[29] A. Anders, Surf. Coat. Technol. 200, 1893 (2005).

[30] J. Hopwood, Plasma Sources Sci. Technol. 1, 109 (1992).

[31] J. H. Keller, Plasma Sources Sci. Technol. 5, 166 (1996).

[32] H. C. Lee, Appl. Phys. Rev. 5, 011108 (2018).

[33] Y. Setsuhara, M. Kamai, S. Miyake, and J. Musil, Jpn. J. Appl. Phys. 36, 4568 (1997).

[34] S. J. Lee, T. H. Kim, B. H. Jeong, K. N. Kim, and G. Y. Yeom, Thin Solid Films 674, 64 (2019).

[35] K. Takenaka, K. Cho, Y. Ohchi, H. Otani, G. Uchida, and Y. Setsuhara, J. Appl. Phys. 54, 06GC02 (2015).

[36] C. H. Lee, T. H. Kim, S. M. Lee, J. W. Bae, K. N. Kim, and G. Y. Yeom, Sci. Adv. Mater. 9, 1187 (2017).

[37] M. D. Groner, F. H. Fabreguette, J. W. Elam, and S. M. George, Chem. Mater. 16, 639 (2004).

[38] S. H. Ko, H. Pan, C. P. Grigoropoulos, C. K. Luscombe, J. M. J. Fréchet, and D. Poulikakos, Nanotechnol. 18, 345202 (2007).

[39] S. H. Ko, I. Park, H. Pan, N. Misra, M. S. Rogers, C. P. Grigoropoulos, and A. P. Pisano, Appl. Phys. Lett. 92, 154102 (2008).

[40] J. You, Z. Hong, Y. Yang, Q. Chen, M. Cai, T. B. Song, C. C. Chen, S. Lu, Y. Liu, H. Zhou, and Y. Yang, ACS Nano 8, 1674 (2014).

[41] S. J. Jung, Y. H. Han, B. M. Koo, J. J. Lee, and J. H. Joo, Thin Solid Films 475, 275 (2005).

[42] S. J. Jung, B. M. Koo, Y. H. Han, J. J. Lee, and J. H. Joo, Surf. Coat. Tech. 200, 862 (2005).

[43] K. Takenaka, K. Cho, Y. Ohchi, H. Otani, G. Uchida, and Y. Setsuhara, Jpn. J. Appl. Phys. 54, 06GC02 (2015).

[44] B. B. Sahu, S. B. Jin, P. J. Xiang, J. B. Kim, and J. G. Han, J. Appl. Phys. 123, 205107 (2018).

[45] K. Takenaka, M. Endo, G. Uchida, and Y. Setsuhara, Appl. Phys. Lett. 112, 152103 (2018).

[46] S. I. Oh, G. Choi, H. Hwang, and W. Lu, IEEE Trans. Electron Dev. 60, 2537 (2013).

[47] D. Raoufi, A. Kiasatpour, H. R. Fallah, and A. S. H. Rozatian, Appl. Surf. Sci. 253, 9085 (2007).

[48] L. Kerkache, A. Layadi, E. Dogheche, and D. Rémiens, J. Phys. D: Appl. Phys. 39, 184 (2006).

[49] D. Matsuo, S. Kishida, Y. Setogucti, Y. Ando, R. Miyanaga, M. N. Fujii, and Y. Uraoka, 24th International Workshop on ActiveMatrix Flatpanel Displays and Devices (Kyoto, Japan, 4-7 July 2017), Vol. P-L2, pp 197-198.

[50] J. W. Lim, H. S. Park, T. H. Park, J. Joo, and J. J. Lee, J. Vac. Sci. Technol. A 18, 524 (2000).

[51] Z. G. Li, M. Mori, S. Miyake, M. Kumagai, H. Saito, and Y. Muramatsu, Surf. Coat. Technol. 193, 345 (2005).

[52] G. R. Lee, H. Kim, H. S. Choi, and J. J. Lee, Surf. Coat. Technol. 201, 5207 (2007).

[53] Y. Nihei, Y. Sasakawa, and K. Okimura, Thin Solid Films 516, 2572 (2008).

[54] W. Kulisch, P. Colpo, P. N. Gibson, G. Ceccone, D. V. Shtansky, E. A. Levashov, M. Jelinek, P. J. M. Philip, and F. Rossi, Appl. Phys. A 82, 503 (2006).

[55] W. Kulisch, P. Colpo, P. N. Gibson, G. Ceccone, D. V. Shtansky, E. A. Levashov, and F. Rossi, Surf. Coat. Technol. 188, 735 (2004).

[56] K. S. Shin, B. B. Sahu, M. Kumar, K. Leksakul, and J. G. Han, J. Phys. D: Appl. Phys. 48, 475303 (2015).

[57] K. Sato, H. Hoshino, M. S. Mian, and K. Okimura, Thin Solid Films 651, 91 (2018).

[58] C. Das, A. Dasgupta, S. C. Saha, and S. Ray, J. Appl. Phys. 91, 9401 (2002).

[59] Y. Mishima, M. Takei, T. Uematsu, N. Matsumoto, T. Kakehi, U. Wakino, and M. Okabe, J. Appl. Phys. 78, 217 (1995).

[60] F. J. Morin, Phys. Rev. Lett. 3, 34 (1959).

[61] X. Ye, H. Zhou, I. Levchenko, K. Bazaka, S. Xu, and S. Xiao, Chemistry Select 3, 8779 (2018). 